\title{
Isoprenaline induced Takotsubo syndrome: Histopathological analyses of female rat hearts
}

\author{
Agnieszka Kołodzińska ${ }^{1}$, Katarzyna Czarzasta ${ }^{2}$, Benedykt Szczepankiewicz ${ }^{3}$, \\ Monika Budnik ${ }^{1}$, Renata Główczyńska ${ }^{1}$, Anna Fojt ${ }^{1}$, Tomasz Ilczuk ${ }^{3}$, \\ Krzysztof Krasuski ${ }^{4,5}$, Sonia Borodzicz ${ }^{1,2}$, Agnieszka Cudnoch-Jędrzejewska², \\ Barbara Górnicka ${ }^{3}$, Grzegorz Opolski ${ }^{1}$
}

${ }^{1}$ Department of Cardiology, Medical University of Warsaw, Poland

${ }^{2}$ Department of Experimental and Clinical Physiology, Laboratory of Center for Preclinical Research,

Medical University of Warsaw, Poland

${ }^{3}$ Department of Pathology, Medical University of Warsaw, Poland

${ }^{4}$ Department of Medical Informatics and Telemedicine, Medical University of Warsaw, Poland ${ }^{5}$ Faculty of Mathematics and Information Science, Warsaw University of Technology, Warsaw, Poland

\begin{abstract}
Background: Takotsubo syndrome (TTS) is a stress-induced disorder affecting mostly postmenopausal women. The aim of the study was to evaluate isoprenaline (ISO) dependent female rat model and histopathological characteristics in TTS.

Methods: Forty-nine Sprague Dawley female rats, 12 weeks old, were injected intraperitoneally with a single dose of ISO at doses $50(n=8), 75(n=6), 100(n=3), 150(n=27)$ and $200(n=5) \mathrm{mg} / \mathrm{kg}$ body weight (bw). The control group $(n=6)$ was injected with physiological saline. The echocardiographic examination to assess wall motion abnormalities took place 24, 48, $72 \mathrm{~h}$, and 7 days post-ISO. Histopathological analysis was performed on the basis of hematoxylin-eosin staining.

Results: The total mortality rate was 3/49 (6.12\%). The optimum dose of ISO to induce TTS was $150 \mathrm{mg} / \mathrm{kg}$ bw and 21/27 (77.77\%) rats showed apical ballooning. Histopathological analysis revealed focal necrosis/apoptosis of cardiomyocytes with inflammatory and fibroblast-like cell infiltration. Foci were the most numerous in the central muscle layer with apical-basal gradient $24,48,72 \mathrm{~h}$ post-ISO $(p<0.05)$. Significant differences were noted $48 \mathrm{~h}$ post-ISO in the central layer in apical vs basal segments $(p=0.0032)$, in the endocardial layer in apical vs basal segments (0.00024) and in mid-cavital vs. basal segments $(p=0.0483)$. The number of foci in endocardium of apical region differ $48 \mathrm{~h}$ post-ISO in rats with a dose of $150 \mathrm{vs} .200 \mathrm{mg} / \mathrm{kg} \mathrm{bw}(p=0.0084)$.

Conclusions: The ISO female rat model of TTS is associated with higher optimum dose and lower mortality in comparison with the male TTS model. TTS presents as a singles cardiomyocyte disorder, foci concerned mainly central muscle layer with apical-basal gradient. (Cardiol J 2022; 29, 1: 105-114)

Key words: Takotsubo syndrome, female rat model, stress-induced cardiomyopathy, reversible heart failure
\end{abstract}

\section{Introduction}

Acute reversible heart failure induced by both emotional and physical stressors characterize Takotsubo syndrome (TTS). Clinical presentation of this pathology is similar to acute myocardial in- farction with an echocardiographic view of the left ventricle (LV) with akinetic apical segments and a ventriculogram that resembles the Japanese pot (called takotsubo) used to capture octopuses. Most interesting is the fact that the syndrome concerns women in about $90 \%$ of the cases [1-4]. The disease

Address for correspondence: Agnieszka Kołodzińska, MD, Assistant Professor, Department of Cardiology, Medical University of Warsaw, ul. Banacha 1a, 02-097 Warszawa, Poland, tel: +48 22 599-19-58, fax: +48 22 599-19-57, e-mail: aa.kolodzinska@wp.pl 
may relapse even after 10 years after the first episode and may reappear anytime in the future $[5,6]$. Mostly, it is observed in individuals between 65 and 70 years old but has even been documented in a 90-year-old woman [7]. The pathophysiology of the disease is unknown. In the literature, several hypotheses have been proposed. TTS may result from multivessel epicardial coronary spasm, or may be associated with coronary microvasculature impairment, or may reflect activation of central neurogenic mechanisms analogous to those evoked by subarachnoid hemorrhage, or finally it can be related to catecholamine cardiotoxicity [8-10]. The last hypothesis presents as the most interesting, because in these patients elevated plasma catecholamine concentrations were observed. Lyon et al. [8] have suggested that the high circulating epinephrine serum level might trigger a switch in cardiomyocyte intracellular signaling after occupation of $\beta 2$-adrenoceptors from $\mathrm{Gs}$ protein to Gi protein that produces a negative inotropic effect. The switch may have a protective role since high levels of $\beta 1$-adrenoceptors Gs protein pathway activation induce apoptotic pathways in the cardiomyocytes $[2,8]$. Mori et al. [11] presented that the canine heart has a higher concentration of $\beta$-adrenoreceptors in the apical myocardium with the concentration gradient decreases from the apex to the base and that may explain apical ballooning typical for TTS. Heart histopathology in TTS has not been studied enough. Human myocardial biopsies revealed interstitial infiltrates consisting of mononuclear lymphocytes, leukocytes, macrophages, and additionally myocardial fibrosis, necrosis and apoptosis [1, 12].

Shao et al. [13] presented a male rat model of TTS related to isoprenaline (ISO) intraperitoneal administration that enables a better understanding of the disease [13]. ISO is a synthetic $\beta$-sympathomimetic amine that is structurally related to epinephrine, which increases myocardial oxygen requirements [14]. TTS may be induced by ISO at doses $\geq 50 \mathrm{mg} / \mathrm{kg}$ body weight (bw) in male rats. Regional akinesia in this model was completely resolved within 7 days. Histopathological analysis revealed lipid accumulation and fibrosis in the region of stunned myocardium [13]. Therefore, the aim of the present study was to characterize the histopathology of ISO induced TTS in female rats since the disease mainly concerns women.

\section{Methods}

The experimental procedures were designed in accordance with and approved by The Local
Animal Research Ethics Committee of the Medical University of Warsaw. In this study, 55 Sprague Dawley female rats were used with a mean bw of $210 \mathrm{~g}$. The rats were housed in a temperature-controlled facility $\left(22-25^{\circ} \mathrm{C}\right)$, humidity $60 \%$ with a $12 \mathrm{~h}$ light/dark cycle and given free access to food and water. A single dose of ISO was intraperitoneally (IP) injected to induce TTS in 49 female rats. Doses of ISO: $50,75,100,150,200 \mathrm{mg} / \mathrm{kg}$ bw were tested to identify the optimum dose and minimum dose necessary to induce LV akinesia in female rats. The control group consisted of 6 female rats that were IP injected with physiological saline $(\mathrm{NaCl})$.

\section{Transthoracic echocardiography}

Baseline echocardiograms were performed for all rats under general anesthesia (ketamine $10 \mathrm{mg} / 100 \mathrm{~g}$ bw with xylazine $1 \mathrm{mg} / 100 \mathrm{~g}$ bw, IP). Two-dimensional images were recorded in short and long axis views. Baseline echocardiographic values were recorded to identify LV akinesia typical for TTS $[13,15,16]$. The transthoracic echocardiography was performed, and the results were analyzed in a blinded manner.

In the control group, echocardiography was performed $24 \mathrm{~h}$ post- $\mathrm{NaCl}$. In the experimental group with a dose of $150 \mathrm{mg} / \mathrm{kg}$ bw, echocardiography was performed $24 \mathrm{~h}$ post-ISO and additionally after $48 \mathrm{~h}(\mathrm{n}=6), 72 \mathrm{~h}(\mathrm{n}=7), 7$ days $(\mathrm{n}=7)$. In the group with a dose of $200 \mathrm{mg} / \mathrm{kg}$ bw, echocardiography was performed $24 \mathrm{~h}$ and $48 \mathrm{~h}$ post-ISO. In the low dose groups: $50-100 \mathrm{mg} / \mathrm{kg} \mathrm{bw}$, echocardiography was performed $6 \mathrm{~h}$ and $24 \mathrm{~h}$ post-ISO.

\section{Takotsubo cardiomyopathy induction}

In 8 rats - an ISO dose of $50 \mathrm{mg} / \mathrm{kg}$ bw was administered, in 6 rats $-75 \mathrm{mg} / \mathrm{kg}$ bw, in 3 rats $-100 \mathrm{mg} / \mathrm{kg}$ bw, in $27 \mathrm{rats}-150 \mathrm{mg} / \mathrm{kg}$ bw, in $5 \mathrm{rats}-200 \mathrm{mg} / \mathrm{kg}$ bw. In the group with a dose of $150 \mathrm{mg} / \mathrm{kg}$ bw, $1 / 27$ died and $6 / 27$ rats were sacrificed $24 \mathrm{~h}$ post-ISO, $6 / 27$ after $48 \mathrm{~h}, 7 / 27$ after $72 \mathrm{~h}$, and $7 / 27$ after 7 days (Fig. 1); in the group with a dose of $200 \mathrm{mg} / \mathrm{kg}$ bw, 5 rats were sacrificed $48 \mathrm{~h}$ post-ISO; and in the control group, 6 rats were sacrificed $24 \mathrm{~h}$ post- $\mathrm{NaCl}$.

\section{Histopathological analysis}

The hearts of the sacrificed animals treated with doses of 150 and $200 \mathrm{mg} / \mathrm{kg}$ bw and from the control group were fixed in $4 \%$ formaldehyde and cut into four fragments: apical, basal, and mid-cavity segments. Additionally, the mid-cavity segments were cut horizontally to identify their central parts. Heart fragments were embedded 


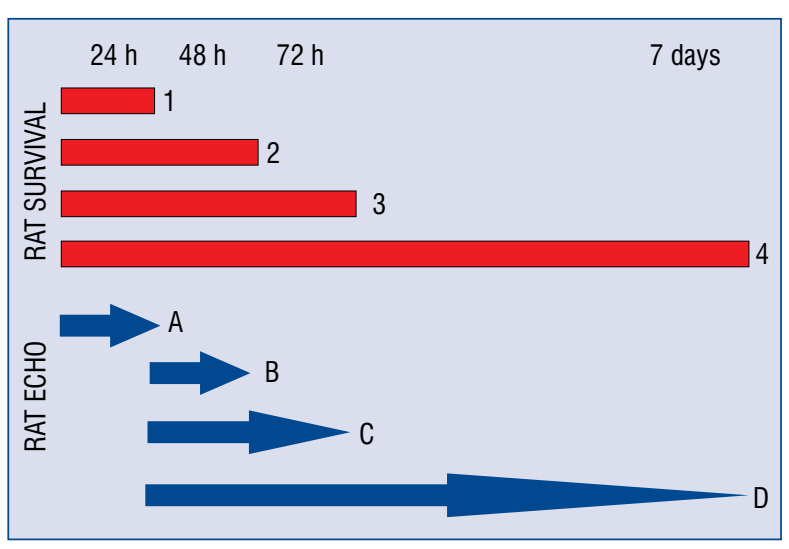

Figure 1. Summary of echocardiography analysis and rat survival in the subgroup treated with the dose 150 $\mathrm{mg} / \mathrm{kg}$ body weight 24 hours post isoprenaline (ISO) administration all (27) animals underwent echo analysis (A) and 1 rat died and 6/27 were sacrificed (1). 48 hours post ISO $6 / 27$ rats underwent echo (B) and were sacrificed (2). 72 hours post ISO 7/27 rats underwent echo (C) and were sacrificed (3). 7 days post ISO $7 / 27$ rats underwent echo (D) and were sacrificed (4).

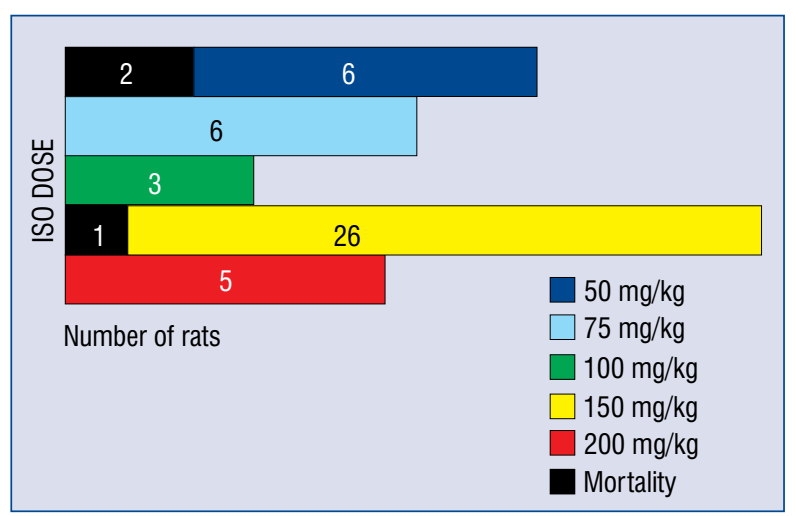

Figure 2. Summary of rat survival and mortality; ISO isoprenaline.

in paraffin and cut into $4 \mu \mathrm{m}$ sections. Finally, hematoxylin and eosin and Trichrom blue staining were performed. The morphological and quantitative studies were performed. Apical, mid-cavity, and basal segments of the right ventricle (RV) and LV were analyzed. Additionally, in all three segments of LV, the epicardial, central, and endocardial muscle layers were evaluated. Inflammatory cells (macrophages, lymphocytes, neutrophils) mobilization and their focal accumulation, mitosis of infiltrating cells, cardiomyocyte vacuolization, cardiomyocyte necrosis/apoptosis, interstitial edema (IE), cardiomyocyte hypertrophy, foam cells, fibroblast-like cells and collagen accumulation were taken into consideration.

\section{Statistical analysis}

The Shapiro-Wilk and Levene tests were used. The Kruskal-Wallis test was performed to identify significant differences between the means of the analyzed values (mean number, \pm standard deviation) and was followed by multiple comparison post-hoc tests. Data was analyzed in the Statistica 10 application. $\mathrm{P}<0.05$ was considered statistically significant.

\section{Results}

\section{Takotsubo syndrome induction by ISO administration in female rats}

Low doses of ISO were associated with a rare presence of motion abnormalities in echocardiography. Only $1 / 8(12.5 \%)$ in the group with an ISO dose of $50 \mathrm{mg} / \mathrm{kg}$ bw, 2/6 (33.3\%) in the $75 \mathrm{mg} / \mathrm{kg}$ bw group, and $0 / 3(0 \%)$ in the $100 \mathrm{mg} / \mathrm{kg}$ bw group possessed features of TTS in echocardiography. An ISO dose of $150 \mathrm{mg} / \mathrm{kg}$ bw appeared to be the optimum dose since $21 / 27(77.77 \%)$ of the rats presented apical akinesia in echocardiographic examination $24 \mathrm{~h}$ post-ISO. A dose of $200 \mathrm{mg} / \mathrm{kg}$ bw was also administered, however, none of the 5 examined rats presented echocardiographic features of TTS. The total mortality rate in the experimental group was $3 / 49(6.12 \%)$ and was observed in the first $24 \mathrm{~h}$ post-ISO ( 2 in the group with an ISO dose of $50 \mathrm{mg} / \mathrm{kg}$ [2/8;25\%] without akinesia typical for TTS, with significant bradycardia; and 1 in the group with an ISO dose of $150 \mathrm{mg} / \mathrm{kg}$ $[1 / 27 ; 3.7 \%]$ with severe bradycardia and extensive LV akinesia) (Figs 1, 2).

\section{Histopathological analysis}

In the control group, $24 \mathrm{~h}$ post- $\mathrm{NaCl}$, normal cardiomyocytes and vasculature of the heart were observed (Fig. 3A, B).

\section{Histopathology: Morphological analysis in the hearts of rats with TTS (post-ISO $150 \mathrm{mg} / \mathrm{kg} \mathrm{bw}$ )}

In the group sacrificed $\mathbf{2 4} \mathrm{h}$ post-ISO, focal cardiomyocyte necrosis/apoptosis and vacuolization of neighboring cardiomyocytes were observed in apical, mid-cavital and basal segments of LV and in RV (Fig. 3C, D). Foci were not observed in the epicardium of LV (Fig. 3), while in RV they were located in all heart muscle layers (Fig. 4). Foci of cardiomyocyte necrosis/apoptosis contained macrophages, fibroblast-like cells and rarely neutrophils. Foci of cardiomyocyte necrosis/apoptosis with inflammatory cells infiltration were much bigger in RV than in LV. Inflammatory cells mobili- 


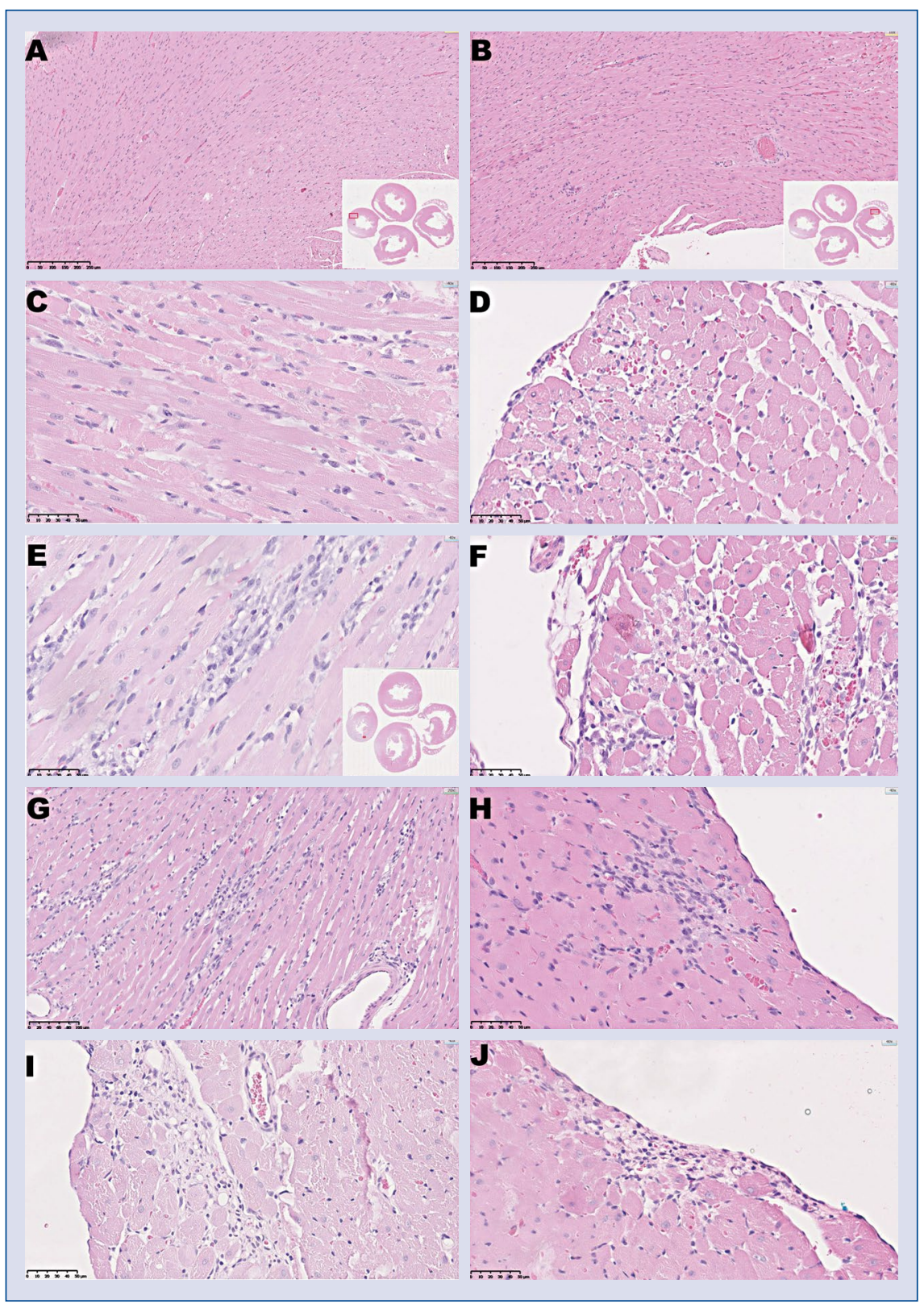

Figure 3. Histopathological abnormalities in the hearts of rats with Takotsubo syndrome (TTS) treated with isoprenaline (ISO) dose $150 \mathrm{mg} / \mathrm{kg}$ body weight in comparison to control rats treated with $\mathrm{NaCl}$; A. Apical segments of myocardium. Normal cardiac muscle and vessels; B. Basal segments of myocardium. Normal cardiac muscle and vessels; C. Apical segment of myocardium $24 \mathrm{~h}$ after ISO administration. Focal necrosis/apoptosis of single cardiomyocytes (less than 5 per foci). Few macrophages and rare neutrophils. Mitosis of infiltrating cells. Features of inflammatory and fibroblast-like cells mobilization; D. Midventricular segments of myocardium $24 \mathrm{~h}$ after ISO administration. Focal single cardiomyocyte necrosis/apoptosis with macrophages, neutrophils infiltration. Vacuolization of cardiomyocytes with few large vacuoles. Interstitial edema with cardiomyocytes drawn aside; E. Apical segments of myocardium $48 \mathrm{~h}$ after ISO administration. Large foci of chronic inflammation, without cardiomyocyte necrosis/apoptosis. Mitosis of infiltrating cells. Less expressed interstitial edema; F. Middle segments of myocardium $48 \mathrm{~h}$ after ISO administration. Focal mononuclear cell infiltration. Interstitial edema. Small hemorrhages. Irregular shape, enlarged cardiomyocytes. Collagen deposits; G. Apical segments of myocardium $72 \mathrm{~h}$ after ISO administration. Large foci of granulation tissue. Mitosis of infiltrating cells. Collagen deposits; H. Middle segments of myocardium $72 \mathrm{~h}$ after ISO administration. Large foci of granulation tissue, chronic inflammation, collagen deposits. Enlarged cardiomyocytes with blur contours and structure; I. Apical segments of myocardium 7 days post ISO administration. Smaller foci of inflammation with fibroblasts and focal fibrosis. The features of cardiac hypertrophy are also visible; J. Middle segments of myocardium 7 days post ISO administration. Smaller subendocardial foci of inflammation with fibroblasts and focal fibrosis. The features of cardiac hypertrophy are also visible. 


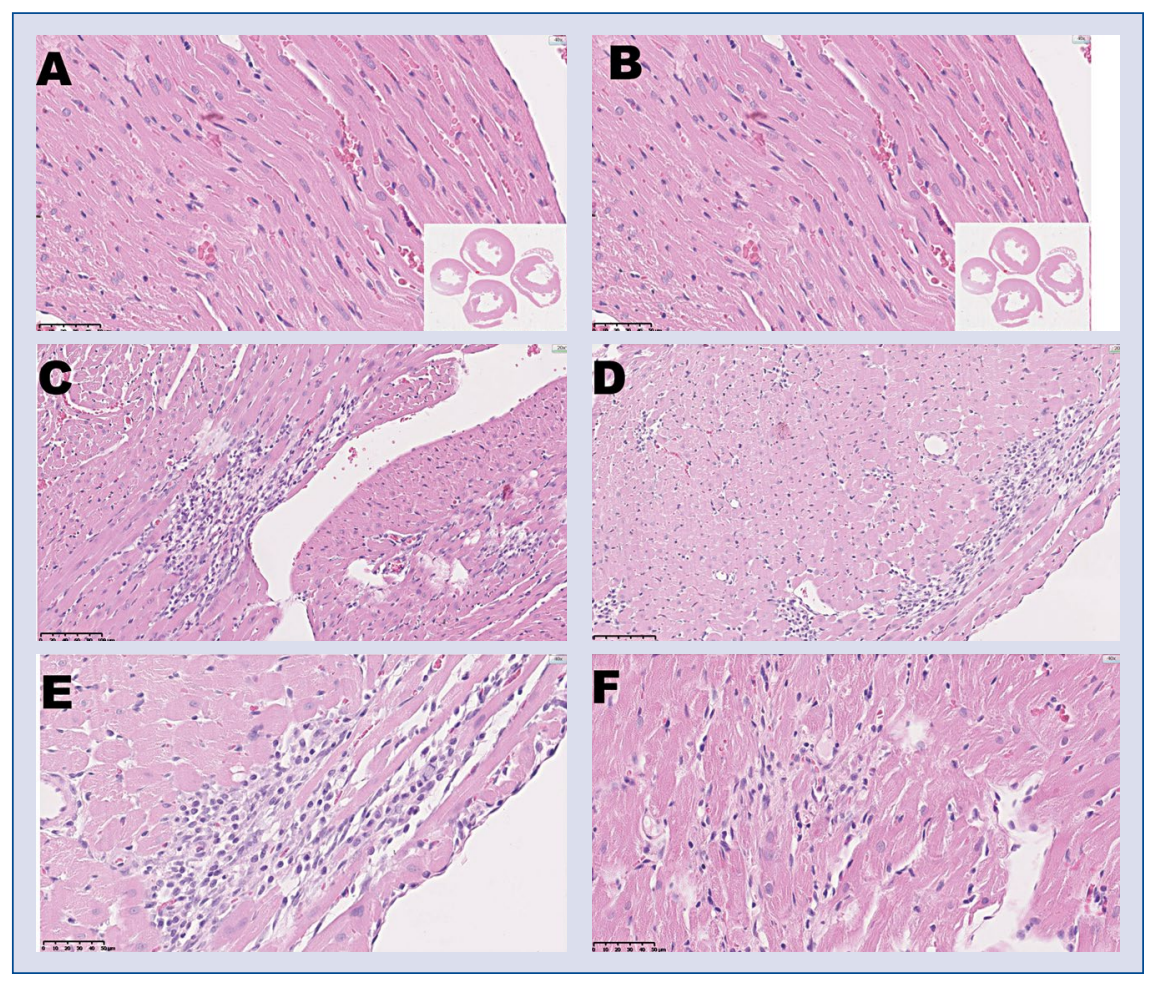

Figure 4. Takotsubo syndrome-histopathological abnormalities in right ventricle (RV); A, B. Control rat hearts. Mid-cavity segments of RV. Normal cardiac muscle and vasculature; C. $24 \mathrm{~h}$ after isoprenaline (ISO) administration. Larger focal cardiomyocyte necrosis/apoptosis with more inflammatory and fibroblast-like cell infiltrations than observed in left ventricle. Cardiomyocyte vacuolization. Slight edema mainly around vessels; D. 48 h after ISO administration. Foci of mononuclear inflammatory cell infiltration. Mitosis of infiltrating cells; E. $72 \mathrm{~h}$ after ISO administration. Foci of granulation tissue. Collagen deposits; F. Seven days after ISO administration. Single smaller foci of inflammatory cell infiltration. Foci of collagen deposits. Features of cardiomyocyte hypertrophy and lipid accumulation. Disrupted architecture of singles cardiomyocytes.

zation were accompanied by features of vascularization. Mitosis of infiltrating cells was observed. IE was visible (Fig. 3C, D).

$48 \mathrm{~h}$ post-ISO larger foci of inflammatory and fibroblast-like cells infiltration with a mononuclear inflammation pattern without cardiomyocyte necrosis/apoptosis were observed. Mitosis of infiltrating cells were seen. Vacuolization of cardiomyocytes was not distinguishable in most rats. IE was less expressed. Foam cells rarely appeared. Additionally, small focal hemorrhages were noticed (Fig. 3E, F).

$72 \mathrm{~h}$ post-ISO foci of granulation tissue were observed, fibroblast-like cells, without damaged cardiomyocytes, without cardiomyocyte vacuolization, without IE but with collagen deposits. Cardiomyocytes neighboring foci were larger with blur contours and structures that may suggest cardiomyocyte edema. Mitosis of infiltrating cells was visible (Fig. $3 \mathrm{G}, \mathrm{H}$ ).
7 days post-ISO $4 / 7$ rats presented normal echocardiographic function of the heart and histopathology revealed almost normal cardiac structure. Small collagen deposits were seen with focal foam cells, single, small, residual foci of inflammation. In 3/7 rats, heart motion abnormalities persisted and histopathological analysis showed rare foci of mononuclear cells, scattered collagen deposits and foam cells. In all hearts diagnosed with TTS, cardiomyocytes focally presented features of hypertrophy (Fig. 3I, J).

\section{Histopathology: Quantitative analysis in the hearts of rats with TTS (post-ISO $150 \mathrm{mg} / \mathrm{kg}$ bw)}

$24 \mathrm{~h}$ post-ISO the number of foci in the endocardial muscle layer was from 0 to 12 in the field of view (i.f.v. $200 \times$ ), 0 to 13 i.f.v. in the central cardiac muscle layer, and 0 to 6 i.f.v. in RV of apical segments. The foci were more numerous in the apical than in basal segments of LV in central muscle layer 
Table 1. The mean number of foci of inflammatory cells, fibroblast-like cells arranged originally in neighborhood of apoptotic/necrotic cardiomyocytes in rats with Takostubo syndrome (TTS).

\begin{tabular}{|c|c|c|c|c|c|c|}
\hline Localization & $\begin{array}{l}24 \text { h post-ISO } \\
(\text { min-max) }\end{array}$ & $\begin{array}{l}48 \text { h post-ISO } \\
\text { (min-max) }\end{array}$ & $\begin{array}{l}72 \text { h post-ISO } \\
\text { (min-max) }\end{array}$ & $\begin{array}{l}7 \text { days post-ISO } \\
(\text { min-max) }\end{array}$ & $\mathbf{P}$ & $\begin{array}{l}7 \text { days post-ISO } \\
\text { without TTS }\end{array}$ \\
\hline $\begin{array}{l}\text { Apical segments; } \\
\text { epicardial layer }\end{array}$ & 0 & $\begin{array}{l}0.2 \pm 0.4 \\
\quad(0-1)\end{array}$ & $\begin{array}{l}0.3 \pm 0.5 \\
(0-1)\end{array}$ & 0 & $>0.05$ & 0 \\
\hline $\begin{array}{l}\text { Apical segments; } \\
\text { central layer }\end{array}$ & $\begin{array}{c}6.8 \pm 4.2 \\
(0-13)\end{array}$ & $\begin{array}{l}7.7 \pm 4.5 \\
(3-13)\end{array}$ & $\begin{array}{c}8.5 \pm 3.8 \\
(4-13)\end{array}$ & $\begin{array}{l}3.3 \pm 2.7 \\
\quad(0-8)\end{array}$ & $>0.05$ & $\begin{array}{c}2.7 \pm 2.1 \\
(1-5)\end{array}$ \\
\hline $\begin{array}{l}\text { Apical segments; } \\
\text { endocardial layer }\end{array}$ & $\begin{array}{c}6.0 \pm 4.3 \\
(0-12)\end{array}$ & $\begin{array}{l}5.8 \pm 1.7 \\
(4-8)\end{array}$ & $\begin{array}{l}3.5 \pm 2.1 \\
\quad(0-5)\end{array}$ & $\begin{array}{l}2.7 \pm 1.5 \\
(0-4)\end{array}$ & $>0.05$ & $\begin{array}{l}3.7 \pm 0.6 \\
(3-4)\end{array}$ \\
\hline $\begin{array}{l}\text { Apical segments; } \\
\text { right ventricle }\end{array}$ & $\begin{array}{l}3.3 \pm 2.3 \\
\quad(0-6)\end{array}$ & $\begin{array}{l}3.0 \pm 1.5 \\
(1-5)\end{array}$ & $\begin{array}{l}2.8 \pm 2.3 \\
(0-7)\end{array}$ & $\begin{array}{c}1.6 \pm 1.7 \\
(0-5)\end{array}$ & $>0.05$ & $\begin{array}{l}1.3 \pm 0.6 \\
(1-2)\end{array}$ \\
\hline $\begin{array}{l}\text { Mid-cavity segments; } \\
\text { epicardial layer }\end{array}$ & 0 & 0 & 0 & 0 & & 0 \\
\hline $\begin{array}{l}\text { Mid-cavity segments; } \\
\text { central layer }\end{array}$ & $\begin{array}{c}3.0 \pm 2.7 \\
(0-8)\end{array}$ & $\begin{array}{l}3.8 \pm 2.0 \\
\quad(1-7)\end{array}$ & $\begin{array}{c}6.3 \pm 4.5 \\
(2-14)\end{array}$ & $\begin{array}{l}1.7 \pm 1.3 \\
(0-2)\end{array}$ & $>0.05$ & $\begin{array}{l}1.7 \pm 0.6 \\
(1-2)\end{array}$ \\
\hline $\begin{array}{l}\text { Mid-cavity segments; } \\
\text { endocardial layer }\end{array}$ & $\begin{array}{l}4.2 \pm 4.4 \\
(0-12)\end{array}$ & $\begin{array}{l}4.3 \pm 2.3 \\
(2-8)\end{array}$ & $\begin{array}{c}6.7 \pm 4.5 \\
(2-11)\end{array}$ & $\begin{array}{l}2.1 \pm 2.3 \\
\quad(0-6)\end{array}$ & $>0.05$ & $\begin{array}{c}1.3 \pm 1.5 \\
(0-3)\end{array}$ \\
\hline $\begin{array}{l}\text { Mid-cavity segments; } \\
\text { right ventricle }\end{array}$ & $\begin{array}{l}3.3 \pm 2.8 \\
(0-8)\end{array}$ & $\begin{array}{l}2.2 \pm 1.5 \\
(0-4)\end{array}$ & $\begin{array}{l}2.7 \pm 2.3 \\
(1-6)\end{array}$ & $\begin{array}{l}1.9 \pm 1.3 \\
(0-4)\end{array}$ & $>0.05$ & $\begin{array}{l}2.0 \pm 2.0 \\
(0-4)\end{array}$ \\
\hline $\begin{array}{l}\text { Basal segments; } \\
\text { epicardial layer }\end{array}$ & 0 & 0 & 0 & 0 & & 0 \\
\hline $\begin{array}{l}\text { Basal segments; } \\
\text { central layer }\end{array}$ & $\begin{array}{l}1.2 \pm 1.0 \\
(0-2)\end{array}$ & $\begin{array}{l}0.8 \pm 1.0 \\
(0-2)\end{array}$ & $\begin{array}{l}2.5 \pm 1.6 \\
(0-4)\end{array}$ & $\begin{array}{c}0.9 \pm 1.2 \\
(0-3)\end{array}$ & $>0.05$ & $\begin{array}{c}1.3 \pm 1.5 \\
(0-3)\end{array}$ \\
\hline $\begin{array}{l}\text { Basal segments; } \\
\text { endocardial layer }\end{array}$ & $\begin{array}{c}1.3 \pm 1.8 \\
(0-4)\end{array}$ & $\begin{array}{l}0.3 \pm 0.8 \\
(0-2)\end{array}$ & $\begin{array}{c}3.0 \pm 4.6 \\
(0-11)\end{array}$ & $\begin{array}{c}1.1 \pm 1.9 \\
(0-5)\end{array}$ & $>0.05$ & $\begin{array}{c}2.3 \pm 2.5 \\
(0-5)\end{array}$ \\
\hline $\begin{array}{l}\text { Basal segments; } \\
\text { right ventricle }\end{array}$ & $\begin{array}{c}2.5 \pm 2.1 \\
(0-6)\end{array}$ & $\begin{array}{l}3.2 \pm 1.6 \\
\quad(1-5)\end{array}$ & $\begin{array}{l}2.8 \pm 2.3 \\
(0-6)\end{array}$ & $\begin{array}{l}1.9 \pm 2.0 \\
(0-4)\end{array}$ & $>0.05$ & $\begin{array}{c}1.7 \pm 2.1 \\
(0-4)\end{array}$ \\
\hline
\end{tabular}

ISO - isoprenaline

$6.8 \pm 4.2$ vs. $1.2 \pm 1.0(\mathrm{p}=0.0449)$. The muscle of RV was equally affected ( $3.3 \pm 2.3$ vs. $3.3 \pm 2.8$ vs. $2.5 \pm 2.1$ i.f.v. of apical, mid-cavital, and basal segments respectively; $p>0.05$ ). Foci of inflammatory cell infiltrations around cardiomyocytes with features of cardiomyocyte necrosis/apoptosis were also frequently seen in the endocardium of the mid-cavity segments $(4.2 \pm 4.4$ i.f.v. in rats with TTS) (Table 1). Cardiomyocyte vacuolization was observed in LV and RV, except the epicardial layer of LV.

$48 \mathrm{~h}$ post-ISO rare cardiomyocyte vacuolization was observed in 3 rats. In the whole heart of the first rat with privilege of phenomena in the central and endocardial layers while in the second and third rats in endocardium of apical and midcavity segments respectively. IE was most frequently observed in the endocardium of the apical region in $4 / 6(66.6 \%)$ rats. In RV, IE was noted in $2 / 6(33.3 \%)$ rats in the apical region of the heart and $1 / 6(16.6 \%)$ rats in the mid-cavity and basal segments. The foci of infiltrating cells were larger, most numerous and were not only visible mainly in the central layer of the apical region $(7.7 \pm 4.5$ i.f.v. $)$ but also in endocardium of mid-cavity segments $(4.3 \pm 2.3$ i.f.v.). In basal segments of the heart's foci were rather rare phenomena relatively most frequently observed in the central layer $(0.8 \pm 1.0$ (Table 1). Statistically significant differences were noted in central layer in apical vs basal segments $(\mathrm{p}=0.0032)$ and in endocardial layer in apical vs. basal segments $(\mathrm{p}=0.00024)$ and in mid-cavital vs. basal segments $(\mathrm{p}=0.0483)$ (Table 1$)$.

$72 \mathrm{~h}$ post-ISO foci seem to predominate in the apical region in central layer $8.5 \pm 3.8$ vs. $2.5 \pm 1.6$ in basal segments $(\mathrm{p}=0.0283)$ (Table 1$)$.

7 days post-ISO single foci were distinguishable with a maximum of $3.3 \pm 2.7$ i.f.v. in apex.

The histopathological analysis of RV revealed (Fig. 4) that the mean number of foci was similar in all segments through all periods of time (Table 1 ). The maximum number of foci in the field of view was 8 . The highest concentration of foci was observed in the papillary muscles. 


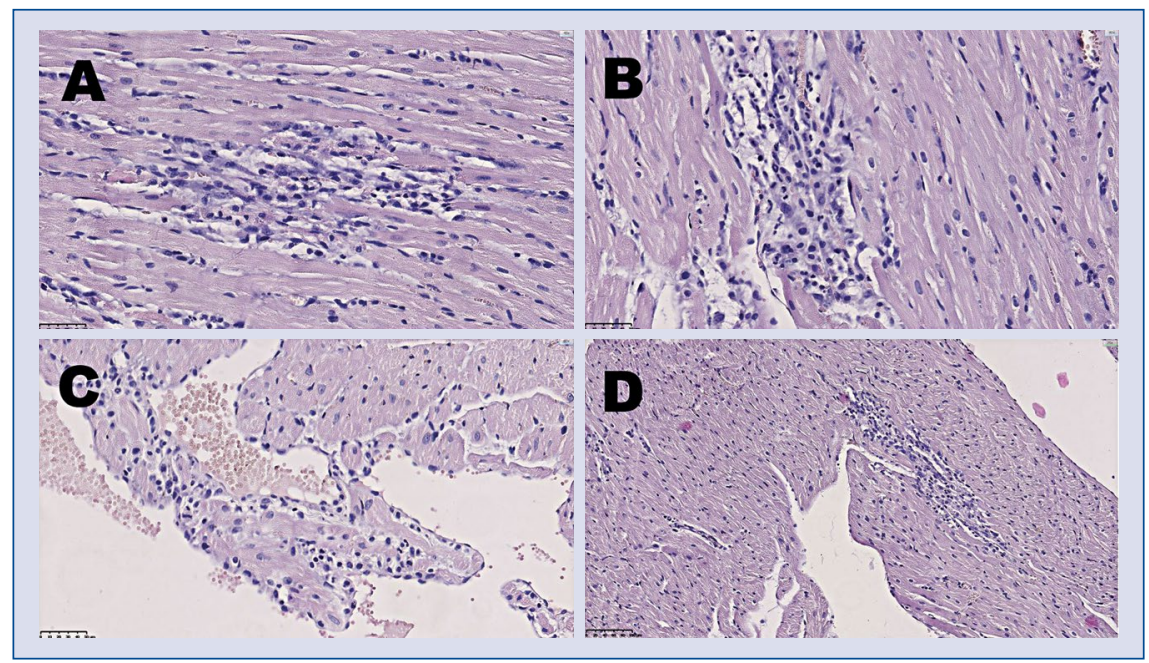

Figure 5. Histopathological abnormalities in female rats $48 \mathrm{~h}$ post isoprenaline (ISO) dose $200 \mathrm{mg} / \mathrm{kg}$ body weight administration without echocardiographical features of Takotsubo syndrome; A. Apical segment of left ventricle (LV). Focal inflammatory cell infiltration; B. Mid-cavity segment of LV. Focal inflammatory cell infiltration; C. Basal segment of LV. Focal inflammatory cells infiltration; D. Right ventricle. Focal inflammatory inflammatory cell infiltration.

Table 2. Comparison of the mean number of foci of cardiomyocyte necrosis/apoptosis and inflammatory cell infiltration between $150 \mathrm{mg} / \mathrm{kg}$ body weight and $200 \mathrm{mg} / \mathrm{kg}$ body weight isoprenaline injected female rats.

\begin{tabular}{lccc}
\hline $\begin{array}{l}\text { Segment } \\
\text { of the heart }\end{array}$ & Localization & $\begin{array}{c}\text { The } \mathbf{m e a n} \text { number of foci } \\
(\mathbf{1 5 0} \mathbf{~ m g} / \mathbf{k g} \text { vs. } \mathbf{2 0 0} \mathbf{~ m g} / \mathbf{k g})\end{array}$ & $P$ \\
\hline Apical & Central layer & $7.7 \pm 4.5$ vs $3.6 \pm 1.5$ & $>0.05$ \\
& Endocardial layer & $5.8 \pm 1.7$ vs $2.8 \pm 1.1$ & $>0.05$ \\
Right ventricle & $3.0 \pm 1.5$ vs. $3.0 \pm 1.7$ & $>0.05$ \\
& Central layer & $3.8 \pm 2.0$ vs. $3.0 \pm 1.4$ & $>0.05$ \\
Endocardial layer & $4.3 \pm 2.3$ vs. $3.4 \pm 1.7$ & $>0.05$ \\
Basal & Right ventricle & $2.2 \pm 1.5$ vs. $2.4 \pm 1.7$ & $>0.05$ \\
& Central layer & $0.8 \pm 1.0$ vs. $1.8 \pm 1.9$ & $>0.05$ \\
& Endocardial layer & $0.3 \pm 0.8$ vs. $1.2 \pm 0.8$ & $>0.05$ \\
& Right ventricle & $3.1 \pm 1.6$ vs. $2.2 \pm 1.3$ & $>0.05$ \\
\hline
\end{tabular}

Histopathology: Rats without features of TTS in echocardiography (post-ISO $200 \mathrm{mg} / \mathrm{kg} \mathrm{bw}$ )

Five female rats received ISO $200 \mathrm{mg} / \mathrm{kg}$ bw, none of them developed echocardiographical features of TTS. In the histopathological analysis, all hearts presented abnormalities. Features of inflammatory cell mobilization was evident in all layers of LV except the epicardium (Fig. 5). The number of foci with inflammatory cell infiltration was significantly less than in the group of rats with TTS induced with a $150 \mathrm{mg} / \mathrm{kg}$ bw dose, $48 \mathrm{~h}$ post-ISO, especially in the endocardium of the apical region $5.8 \pm 1.7$ vs. $2.8 \pm 1.1(\mathrm{p}=0.0084)$ (Table 2$)$.
IE was rarely seen but was present in $3 / 5$ rats in the endocardial layer of the apical segments. Cardiomyocyte vacuolization was not observed.

\section{Heart fibrosis in TTS}

Trichorme blue staining revealed mild fibrosis typical for TTS in both acute and recovery phases (Fig. 6).

\section{Discussion}

There are a few animal based studies related to TTS and fewer still in female rats according to available research. The main findings concern the 


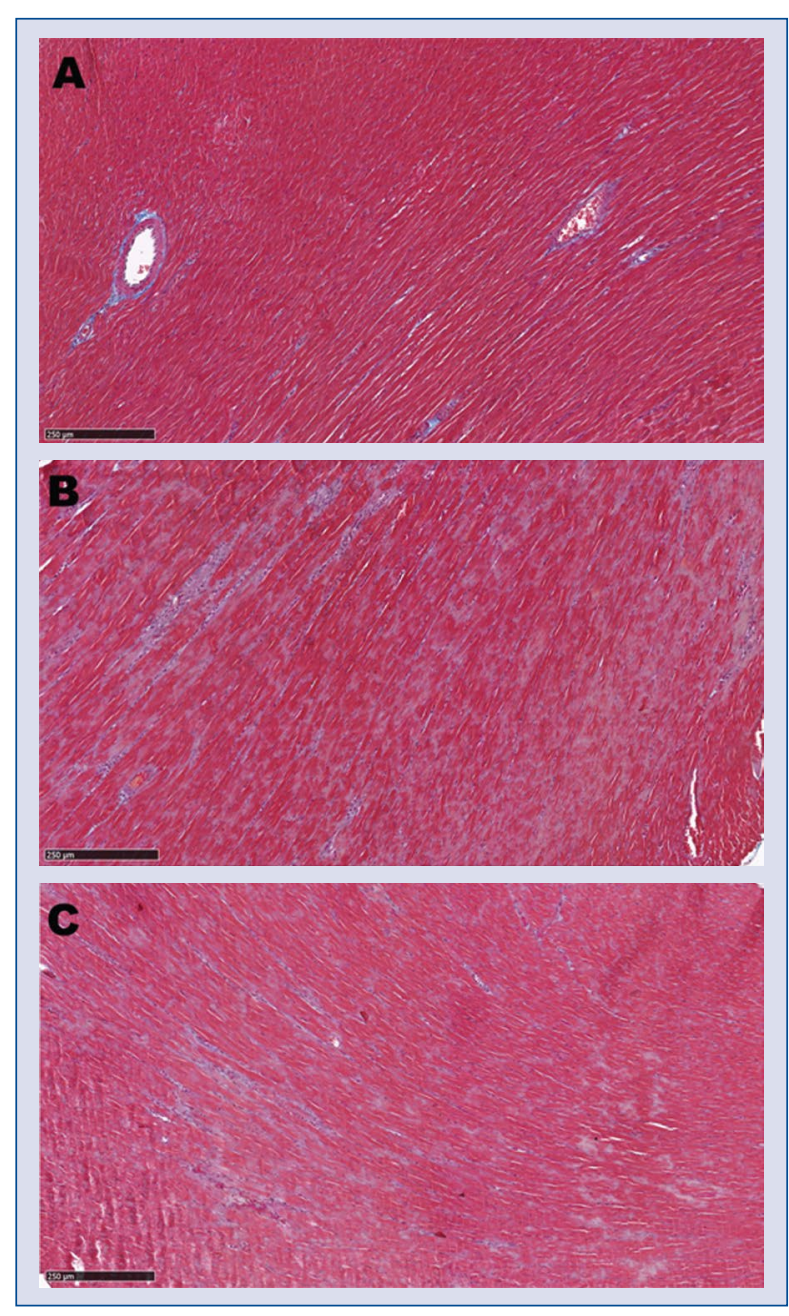

Figure 6. Trichrome blue staining revealed fibrosis; A. Control rat; B. Acute phase of Takotsubo syndrome - mild fibrosis; C. Recovery phase of Takotsubo syndrome - mild fibrosis.

characterization of ISO based female rat model of TTS. Histopathological analysis revealed that TTS is associated with multiple, singles cardiomyocytes apoptosis/necrosis with inflammatory and fibroblast-like cells infiltrations, mainly in the central muscle layer with apical-basal gradient. TTS presents as a disease of the whole heart with the strongest histopathological and echocardiographic expression in LV apex and RV.

In the present study both low (50-100 mg/kg bw) and high (200 mg/kg bw) doses of ISO were ineffective in TTS induction. Shao et al. [13] tested male Sprague Dawley rats with different doses of ISO. An ISO dose of $25 \mathrm{mg} / \mathrm{kg}$ bw did not induce apical ballooning [13]. High frequency TTS occurred at an ISO dose of $50 \mathrm{mg} / \mathrm{kg}$ bw, and the incidence did not increase with higher doses of ISO (100-600 mg/kg bw). In the current study the optimum dose of ISO that induced TTS in adult female rats appeared to be $150 \mathrm{mg} / \mathrm{kg}$ bw with effectiveness $77.77 \%$. All TTS cases presented apical akinesia. Shao et al. [13] noticed atypical basal and midmyocardial akinesia with preservation of apical contractility in four rats, two treated with an ISO dose of $150 \mathrm{mg} / \mathrm{kg}$ bw and two with $450 \mathrm{mg} / \mathrm{kg}$ bw. Redfors et al. [17] showed that not only isoprenaline but all other catecholamines (epinephrine, norepinephrine, dopamine, phenylephrine) may induce TTS. They presented that an ISO dose of $50 \mathrm{mg} / \mathrm{kg}$ bw induced mainly typical apical akinesia while substances with alfa-adrenergic activation, such as epinephrine, mainly revers-TTS [17].

The total mortality was $6.12 \%$ and in the 150 $\mathrm{mg} / \mathrm{kg} / \mathrm{bw}$ group $3.7 \%$ and was lower than reported, occurring in all rats in the first $24 \mathrm{~h}$ post-ISO. Shao et al. [13] observed a high mortality associated with ISO doses $\geq 300 \mathrm{mg} / \mathrm{kg}$ bw. At doses $\leq 150 \mathrm{mg} / \mathrm{kg}$ bw, death occurred only in male rats that developed severe TTS with akinetic area $>30 \%$ of total LV area. All deaths were noticed 48 hours post-ISO and concerned 7 (29.2\%) animals. Seven-day mortality was $50 \%$ in rats that received $50 \mathrm{mg} / \mathrm{kg}$ bw [13].

Little is known about cardiac histopathology in TTS. In humans, there are a few case reports and short series of patients that underwent heart biopsy. Iacucci et al. [18] analyzed a cardiovascular magnetic resonance with heart biopsies in TTS. They observed that the severity of edema was directly proportional to the wall abnormality and low ejection fraction in patients and they also noticed inflammatory cell presence and disrupted myofibres. In a patient that died in the course of TTS, multiple necrotic lesion, monocytes and neutrophils infiltration, as well as hemorrhages were distinguished [19]. Shao et al. [13] reported lipotoxicity with lipid accumulation in the akinetic region that was resolved with the recovery of wall motion abnormalities. Sachdeva et al. [20] in the male rat TTS model with subcutaneous ISO administration presented multiple foci of necrosis scattered among the normal myofibres, mononuclear cell infiltration, and profuse IE in the apical-midventricular region of both ventricles. Moreover, in the biopsied myocardium of 8 females, catecholamine induced apoptosis of the endothelial cells of coronary microvessels was observed and was indicated as the missing link between stress and TTS.

In the present study, focal singles cardiomyocyte necrosis/apoptosis was only seen $24 \mathrm{~h}$ post-ISO. Vacuolization of cardiomyocytes was characteristic for the acute phase. IE was typical $24 \mathrm{~h}$ post-ISO and concerned all segments of RV 
and LV except the epicardial zone. IE gradually diminished up to $48 \mathrm{~h}$ post-ISO, and finally was not distinguishable $72 \mathrm{~h}$ post-ISO. Because of a transient character of IE and persistence of motion abnormalities, even throughout 7 days, the hypothesis raised by Iacucci et al. [18] concerning the association between edema and motion abnormalities needs further evaluation. The features of vascularization, inflammatory and fibroblast-like cell mobilization were visible. The number and size of foci of inflammatory cell infiltrations increased from $24 \mathrm{~h}$ to $72 \mathrm{~h}$ post-ISO but were smaller than presented in the study of Sachdeva et al. [20] where the foci affected even the full thickness of LV. The apical-basal gradient of foci $24,48,72 \mathrm{~h}$ post-ISO based on the mean number of foci resemble the $\beta$-adrenoreceptors apical-basal gradient with the most numerous foci similar to $\beta$-adrenoreceptors accumulation in the apical region. Foci were the most numerous in central and endocardial heart muscle layers, rarely appearing in epicardial zone. In the foci TLR2, TLR4, TLR6 positive mononuclear cells and TLR4CD68 as well as TLR6CD68 positive cells were distinguishable [21]. Apoptosis concerned singles cardiomyocytes 24 h post-ISO, inflammatory cells in the whole course of TTS, and endothelial cells of the vessels 7 days postISO [21]. Moreover 7 days post-ISO a rare foci of inflammation with mild fibrosis was observed and the features of cardiomyocyte hypertrophy were recognized. The features of cardiomyocyte hypertrophy may be explained by the activation of $\beta 1$ receptors that leads to phosphorylation of the L-type calcium channel and calcineurin signaling activation that leads to hypertrophy [22]. TLR4 expression in cardiomyocytes was previously documented [21]. Timmers et al. [23] observed that TLR4 defectiveness was associated with a reduction of interstitial fibrosis and cardiac hypertrophy in the non-infarcted area. TLR4 pathway may play relevant role in TTS. Both echocardiographic and histopathological features of TTS persisted longer in female rat model than in male rats as was reported in the literature by Shao et al. [13].

In the current study, female rats were used. Estrogen receptors are expressed in the cardiomyocytes and can directly act to reduce reactivity of the heart to catecholamines [24]. Ueyama et al. [25] presented that reduction of estrogen levels may explain the high incidence of TTS in ovariectomized (OVX) rats in comparison with estradiolsupplemented OVX animals. Thawornkaiwong et al. [26] showed upregulation of $\beta 1$-adrenoreceptors in OVX rat hearts and proved that estrogen/proges- terone supplementation reversed these changes. A lack of estrogen replacement in the postmenopausal state may predispose women to TTS [27].

\section{Conclusions}

In the female rat model of apical ballooning induced by a single dose of ISO intraperitoneal administration, TTS presents as a disorder of the single cardiomyocytes of both ventricles with a different prevalence between apical and basal segments, mainly in the central muscle layer and with significant inflammatory reaction.

\section{Acknowledgments}

We greatly appreciate Mrs. Dorota Nostachowska for their skillful technical assistance.

Funding: Internal founds of Medical University of Warsaw.

\section{Conflict of interest: None declared}

\section{References}

1. Akashi YJ, Goldstein DS, Barbaro G, et al. Takotsubo cardiomyopathy: a new form of acute, reversible heart failure. Circulation. 2008; 118(25): 2754-2762, doi: 10.1161/CIRCULATIONAHA.108.767012, indexed in Pubmed: 19106400.

2. Hafiz AM, Jan MF, Paterick TE. Takotsubo Cardiomyopathy. 2012; 30: 683-708 in Cardiomyopathies - from basic research to clinical management. Edited by Prof. J. Veselka. Publisher InTech. Published 15.02.2012.

3. Templin C, et al. Ghadri JR, Diekmann J Clinical features and outcomes of Takotsubo (stress) cardiomyopathy. N Engl J Med. 2015; 373: 929-38.

4. Opolski G, Pawlak MM, Roik MF, et al. Clinical presentation, treatment, and long-term outcomes in patients with takotsubo cardiomyopathy. Experience of a single cardiology center. Pol Arch Med Wewn. 2010; 120(6): 231-236, indexed in Pubmed: 20567207.

5. Opolski G, Kochanowski J, Torbicki A, et al. The recurrence after ten years - "mother in-law variant" of tako-tsubo syndrome. Kardiol Pol. 2010; 68(5): 557-561, indexed in Pubmed: 20491020.

6. Opolski G, Budnik M, Kochanowski J, et al. Four episodes of takotsubo cardiomyopathy in one patient. Int J Cardiol. 2016; 203: 53-54, doi: 10.1016/j.ijcard.2015.10.048, indexed in Pubmed: 26512818.

7. Budnik M, Piatkowski R, Kochanowski J, et al. The oldest patient with takotsubo cardiomyopathy. J Geriatr Cardiol. 2015; 12(5): 588-589, doi: 10.11909/j.issn.1671-5411.2015.05.014, indexed in Pubmed: 26512253.

8. Lyon AR, Rees PSC, Prasad S, et al. Stress (Takotsubo) cardiomyopathy--a novel pathophysiological hypothesis to explain catecholamine-induced acute myocardial stunning. Nat Clin Pract Cardiovasc Med. 2008; 5(1): 22-29, doi: 10.1038/ncpcardio1066, indexed in Pubmed: 18094670. 
9. Wright PT, Tranter MH, Morley-Smith AC, et al. Pathophysiology of takotsubo syndrome: temporal phases of cardiovascular responses to extreme stress. Circ J. 2014; 78(7): 1550-1558, doi: 10.1253/circj.cj-14-0623, indexed in Pubmed: 24954393.

10. Coupez E, Eschalier R, Pereira B, et al. A single pathophysiological pathway in Takotsubo cardiomyopathy: Catecholaminergic stress. Arch Cardiovasc Dis. 2014; 107(4): 245-252, doi: 10.1016/j.acvd.2014.04.001, indexed in Pubmed: 24796853.

11. Mori H, Ishikawa S, Kojima S, et al. Increased responsiveness of left ventricular apical myocardium to adrenergic stimuli. Cardiovasc Res. 1993; 27(2): 192-198, doi: 10.1093/cvr/27.2.192, indexed in Pubmed: 8386061.

12. Uchida Y, Egami H, Uchida Y, et al. Possible participation of endothelial cell apoptosis of coronary microvessels in the genesis of Takotsubo cardiomyopathy. Clin Cardiol. 2010; 33(6): 371-377, doi: 10.1002/clc.20777, indexed in Pubmed: 20556810.

13. Shao Y, Redfors B, Scharin Täng M, et al. Novel rat model reveals important roles of $\beta$-adrenoreceptors in stress-induced cardiomyopathy. Int J Cardiol. 2013; 168(3): 1943-1950, doi: 10.1016/j. ijcard.2012.12.092, indexed in Pubmed: 23357048.

14. Young P. The Intensive Care Unit Drug Manual. Life in the Fast Lane. 2010.

15. Watson LE, Sheth M, Denyer RF, et al. Baseline echocardiographic values for adult male rats. J Am Soc Echocardiogr. 2004; 17(2): 161-167, doi: 10.1016/j.echo.2003.10.010, indexed in Pubmed: 14752491.

16. Weytjens C, Cosyns B, D’hooge J, et al. Doppler myocardial imaging in adult male rats: reference values and reproducibility of velocity and deformation parameters. Eur J Echocardiogr. 2006; 7(6): 411-417, doi: 10.1016/j.euje.2006.03.009, indexed in Pubmed: 16672194.

17. Redfors B, Ali A, Shao Y, et al. Different catecholamines induce different patterns of takotsubo-like cardiac dysfunction in an apparently afterload dependent manner. Int J Cardiol. 2014; 174(2): 330-336, doi: 10.1016/.j.jcard.2014.04.103, indexed in Pubmed: 24794965.

18. Iacucci I, Carbone I, Cannavale G, et al. Myocardial oedema as the sole marker of acute injury in Takotsubo cardiomyopathy: a cardiovascular magnetic resonance (CMR) study. Radiol Med. 2013; 118(8): 1309-1323, doi: 10.1007/s11547-013-0931-1, indexed in Pubmed: 23716287.
19. Elsokkari I, Cala A, Khan S, et al. Takotsubo cardiomyopathy: not always innocent or predictable. A unique post mortem insight. Int J Cardiol. 2013; 167(2): e46-e48, doi: 10.1016/j.ijcard.2013.03.090, indexed in Pubmed: 23602295.

20. Sachdeva J, Dai W, Kloner RA. Functional and histological assessment of an experimental model of Takotsubo's cardiomyopathy. J Am Heart Assoc. 2014; 3(3): e000921, doi: 10.1161/ JAHA.114.000921, indexed in Pubmed: 24958782.

21. Kołodzińska A, Czarzasta K, Szczepankiewicz B, et al. Toll-like receptor expression and apoptosis morphological patterns in female rat hearts with takotsubo syndrome induced by isoprenaline. Life Sci. 2018; 199: 112-121, doi: 10.1016/j.lfs.2018.02.042, indexed in Pubmed: 29501923.

22. Frey N, Katus HA, Olson EN, et al. Hypertrophy of the heart: a new therapeutic target? Circulation. 2004; 109(13): 1580-1589, doi: 10.1161/01.CIR.0000120390.68287.BB, indexed in Pubmed: 15066961.

23. Timmers L, Sluijter JPG, van Keulen JK, et al. Toll-like receptor 4 mediates maladaptive left ventricular remodeling and impairs cardiac function after myocardial infarction. Circ Res. 2008; 102(2): 257-264, doi: 10.1161/CIRCRESAHA.107.158220, indexed in Pubmed: 18007026.

24. Ueyama T, Kasamatsu K, Hano T, et al. Catecholamines and estrogen are involved in the pathogenesis of emotional stress-induced acute heart attack. Ann N Y Acad Sci. 2008; 1148: 479-485, doi: 10.1196/annals.1410.079, indexed in Pubmed: 19120144.

25. Ueyama T, Hano T, Kasamatsu K, et al. Estrogen attenuates the emotional stress-induced cardiac responses in the animal model of Tako-tsubo (Ampulla) cardiomyopathy. J Cardiovasc Pharmacol. 2003; 42 Suppl 1: S117-S119, doi: 10.1097/00005344200312001-00024, indexed in Pubmed: 14871041.

26. Thawornkaiwong A, Preawnim S, Wattanapermpool J. Upregulation of beta 1 -adrenergic receptors in ovariectomized rat hearts. Life Sci. 2003; 72(16): 1813-1824, doi: 10.1016/s00243205(02)02473-6, indexed in Pubmed: 12586219.

27. Kuo BT, Choubey R, Novaro GM. Reduced estrogen in menopause may predispose women to takotsubo cardiomyopathy. Gend Med. 2010; 7(1): 71-77, doi: 10.1016/j.genm.2010.01.006, indexed in Pubmed: 20189157. 